\title{
Behaviour of Water Droplets Under the Influence of a Uniform Electric Field in Nanocomposite Samples of Epoxy Resin/ $\mathrm{TiO}_{2}$
}

\author{
A. Bairaktari \\ Democritus \\ University of \\ Thrace, \\ Dpt of Electrical \\ and Computer \\ Engineering, \\ Power Systems \\ Lab, Greece \\ agbairaktari@ \\ gmail.com
}

\author{
M. G. Danikas \\ Democritus \\ University of \\ Thrace, \\ Dpt of Electrical \\ and Computer \\ Engineering, \\ Power Systems \\ Lab, Greece \\ mdanikas@ \\ ee.duth.gr
}

\author{
X. Zhao \\ Xi'an Jiaotong \\ University, \\ State Key \\ Laboratory of \\ Electrical \\ Insulation and \\ Power Equipment, \\ Xi'an, P. R. China \\ tuan.zx@ \\ stu.xjtu.edu.cn
}

\author{
Y. Cheng \\ Xi'an Jiaotong \\ University, \\ State Key \\ Laboratory of \\ Electrical \\ Insulation and \\ Power Equipment, \\ Xi'an, P. R. China \\ cyh@ \\ mail.xjtu.edu.cn
}

\author{
Y. Zhang \\ Xi'an Jiaotong \\ University, \\ State Key \\ Laboratory of \\ Electrical \\ Insulation and \\ Power Equipment, \\ Xi'an, P. R. China \\ zy0026@ \\ stu.xjtu.edu.cn
}

\begin{abstract}
In this paper nanocomposite samples of epoxy resin and $\mathrm{TiO}_{2}$ nanoparticles were investigated with water droplets on their surface. A uniform electric field was applied and the behaviour of the water droplets was observed. Parameters that were studied were the water conductivity, the droplet volume, the number of droplets and the droplet positioning with respect to (w.r.t.) the electrodes. All above mentioned parameters influence the flashover voltage of the samples. It is to be noted that - at least in some cases - the water droplet positioning w.r.t. the electrodes was more important in determining the flashover voltage than the droplet volume.
\end{abstract}

Keywords- flashover voltage; surface discharges; nanocomposites; uniform electric field; water droplet; water conductivity

\section{INTRODUCTION}

Epoxy resin is an insulating material widely used in high voltage various applications $[1,2]$. Traditional base polymeric materials improve their electrical properties when they are mixed with small percentages of nanoparticles [3]. Addition of small quantities of nanoparticles in percentages weight smaller than $10 \%$ also improve the thermal and mechanical properties of the nanocomposites. For such materials, the interfaces play a most important role [4]. Nanocomposite polymers may be classified in intercalated nanocomposites (formed when there is limited inclusion of polymer chain between the clay layers with a correspondingly small increase in the interlayer spacing of a few nanometers) and exfoliated nanocomposites (which are structures formed when the clay layers are well separated from one another and individually dispersed in the continuous polymer matrix) [5].

Nanocomposite polymers present higher breakdown strength than their base counterparts [6]. Space charges have a much more even distribution in nanocomposite polymers than in base polymers [7]. The thermal conductivity of nanocomposite polymers is also improved compared with their base polymer counterparts [8]. Electrical treeing behaviour is also improved in nanocomposites [9, 10]. The addition of nanoparticles in conventional polymers helps also in increasing their resistance against partial discharges (PD) [11].

In this paper, epoxy resin with $\mathrm{TiO}_{2}$ nanoparticles was investigated. Samples with $1 \%$ and $3 \%$ weight percent (wt) were tested. The purpose of this work was to see how water droplets arrangements on the surface of such samples under the effect of uniform electric field affect the flashover voltage. Parameters, such as water droplet conductivity, number of droplets, droplet volume and droplet positioning w.r.t. the electrodes were examined.

\section{WATER DROPLETS ON POLYMER SURFACES AND THE FACTOR OF HYDROPHOBICITY}

The forces acting on a droplet on a solid insulating surface, in case no electric field is applied, are the surface tension of the liquid, the surface tension of the solid and the interfacial tension between the droplet and the solid. An applied electric field results in a deformation/elongation of the droplet. This deformation will eventually influence the distribution of the electric field. Local field intensifications may ensue and microdischarges may occur between droplets. Such a mechanism may cause the formation of dry zones and the root of the electrochemical deterioration of the insulator surface [12].

Most polymeric materials used for outdoor applications have some sort of hydrophobicity, i.e. the capability of retaining discrete droplets on the insulator surface. Loss of hydrophobicity may result from surface discharges, pollution of the insulator surface and/or from ultraviolet radiation. 
The contact angle is given as

$\theta=90-\tan ^{-1}\left[\frac{r-b}{\sqrt{2 r b-b^{2}}}\right]$

where $b, \theta$ and $r$ as in Figure 1 .

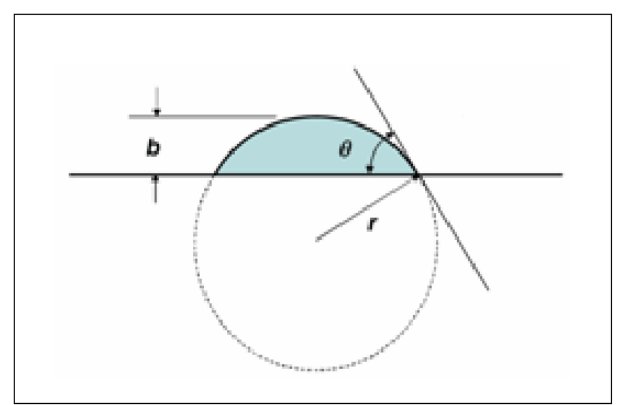

Fig. 1. Model for the calculation of contact angle

Generally speaking, when a water droplet is positioned on a nanocomposite surface under a high electric field parallel to the surface, discharges may appear and surface tension may be reduced with the increase of temperature at the edge of the droplet. In this way, the droplet starts deforming and continuous discharges may ensue between the edges of the droplet and the electrodes [14].

\section{EXPERIMENTAL ARRANGEMENT}

The voltage was supplied from a $20 \mathrm{kV}$ transformer. The dimensions of the electrodes are shown in Figure 2. The electrodes were made of copper and they are half cylindrical with rounded edges. No asperities were allowed on the electrode surfaces. They were positioned on the epoxy resin sample at a distance of $2.5 \mathrm{~cm}$ from each other. The aim of the experiments was to measure the flashover voltage with different droplet arrangements at different conductivities.

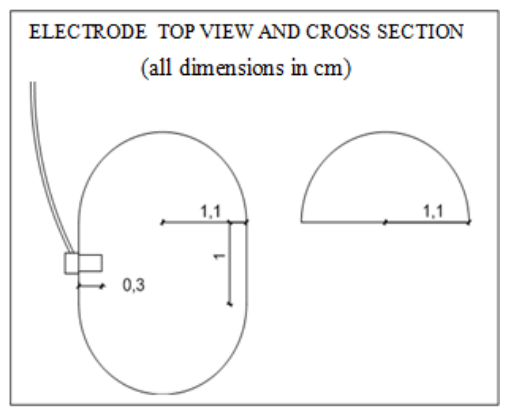

Fig. 2. Top view of one of the electrodes and cross section

The water droplets were positioned on the sample surface with the aid of a special arrangement consisting of a metallic frame and three rules, one of which had two laser indicators. The water droplets were poured into the sample surface with the aid of a syringe. The droplet arrangements are shown in Figure 3, with all dimensions given in $\mathrm{cm}$.

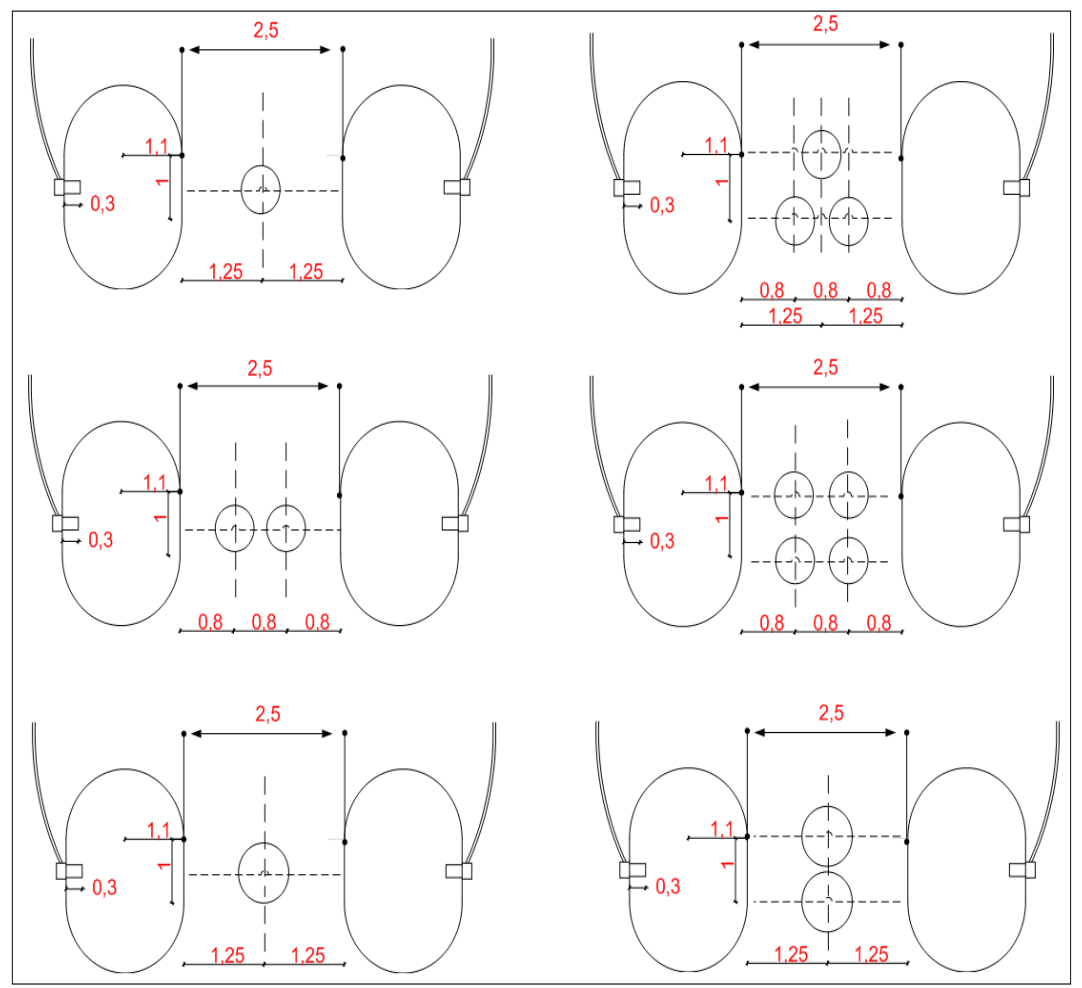

Fig. 3. Droplet arrangements for the experiments (all dimensions in $\mathrm{cm}$ ) 
The conductivities investigated were $1.4 \mu \mathrm{S} / \mathrm{cm}, 100$ $\mu \mathrm{S} / \mathrm{cm}, 200 \mu \mathrm{S} / \mathrm{cm}, 500 \mu \mathrm{S} / \mathrm{cm}, 1000 \mu \mathrm{S} / \mathrm{cm}, 2000 \mu \mathrm{S} / \mathrm{cm}, 5000$ $\mu \mathrm{S} / \mathrm{cm}$ and $10000 \mu \mathrm{S} / \mathrm{cm}$. The conductivity measurements were performed with the aid of an electronic measuring device of conductivity of Type WTW inoLab cond Level 1 with a probe WTW Tetracon 325 (Figure 4).

The following droplet arrangements were used: 1) one droplet of $0.05 \mathrm{ml}$ volume each, 2) two droplets of $0.05 \mathrm{ml}$ volume with a distance of $0.8 \mathrm{~cm}$ between their centres, 3) three droplets of $0.05 \mathrm{ml}$ volume each, forming a triangle, 4) four droplets of $0.05 \mathrm{ml}$ each, 5) one droplet of $0.1 \mathrm{ml}$ volume at a distance of $1.25 \mathrm{~cm}$ from the electrodes and 6) two droplets of $0.1 \mathrm{ml}$ each at a distance of $1 \mathrm{~cm}$ from each other and 1.25 $\mathrm{cm}$ from the electrodes. In Figure 5, various droplet arrangements on the nanocomposite samples are shown

The surface roughness of the samples was measured with the aid of a Perthen Type Perthometer M4P device. Surface roughness for the epoxy nanocomposite samples of $1 \% \mathrm{wt}$ was 0.19 and $0.20 \mu \mathrm{m}$ and for the $3 \% \mathrm{wt}$ nanocomposite samples was $0.15 \mu \mathrm{m}$ and $0.20 \mu \mathrm{m}$.

After positioning the droplets on the epoxy resin surface, the voltage was slowly raised until flashover occurred. After that and after cleaning the surface and positioning new droplets on it, the voltage was raised up to the previous flashover value minus $1.2 \mathrm{kV}$, so that no new flashover would occur. At this voltage value, the arrangements would stay for $5 \mathrm{~min}$. If no flashover occurred, the voltage was raised by $0.4 \mathrm{kV}$ and the procedure was repeated until flashover occurred. The new flashover value was recorded. The reason for allowing the voltage for $5 \mathrm{~min}$ at each voltage level was because a certain time was required for the droplets to deform and for the PD to start.

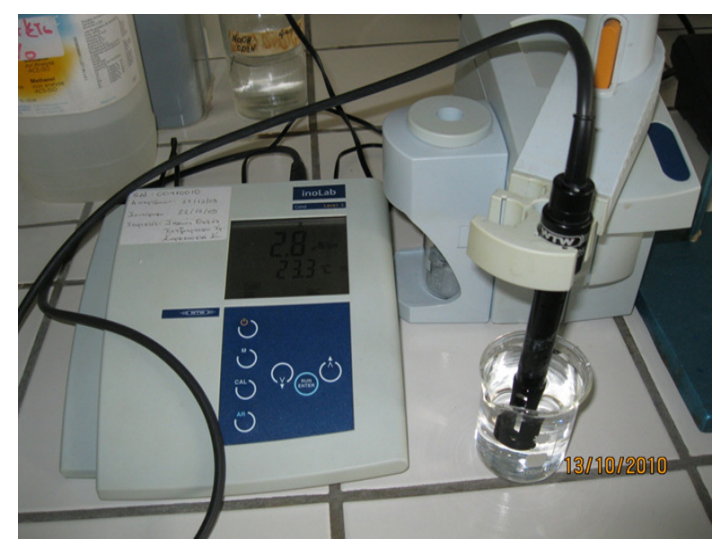

Fig. 4. Device for conductivity measurements

\section{EXPERIMENTAL RESULTS AND DISCUSSION}

In Figures 6 and 7 the experimental results with the various droplet arrangements, the different water conductivities and droplet volumes are given.

It is evident that water conductivity and droplet volume have an inportant effect on flashover voltage, i.e. a larger droplet volume may imply a shorter distance of the droplets from the respective electrodes. If we compare, for example, the results between the droplet of $0.1 \mathrm{ml}$ and that of $0.05 \mathrm{ml}$, we see that the latter gives higher flashover voltage for both investigated nanocomposites. The number of droplets is also a factor not to be neglected. Increasing water conductivity implies a reduced flashover voltage for both nanocomposites, irrspective of their content in $\mathrm{TiO}_{2}$ nanoparticles. Another significant parameter affecting the flashover voltage of the nanocomposite is the positioning of the droplets w.r.t. the electrodes. Having in mind the water droplet arrangements used, if we compare, for example, the results between the arrangement with two droplets of $0.05 \mathrm{ml}$ each and the arrangement of two droplets of $0.1 \mathrm{ml}$ each, we realize that the latter offers a higher flashover voltage than the former. This is valid for both nanoparticle contents. It is indicated from the above figures that the distance of the droplets from the electrodes plays an important role and - sometimes - a more critical than the droplet volume. If the results of Figure 6 and Figure 7 are compared with those of pure epoxy resin (i.e. without any nanoparticles, Figure 8 [15]), it is evident that the addition of nanoparticles improves the flashover voltage of epoxy resin.

The nanocomposite epoxy resin is proven to give higher flashover voltages than the epoxy resin without nanoparticles. Of the two nanocomposite polymers investigated here, the one with $1 \%$ wt has the superior flashover voltage for most droplet arrangements. Evidently, the optimum percentage of nanoparticles depends on the base material as well as on the nature of the nanoparticles. The addition of nanoparticles can improve the flashover voltage of a polymeric material up to a certain point. If a larger percentage of nanoparticles is added, the electrical properties of the nanomaterial may deteriorate.

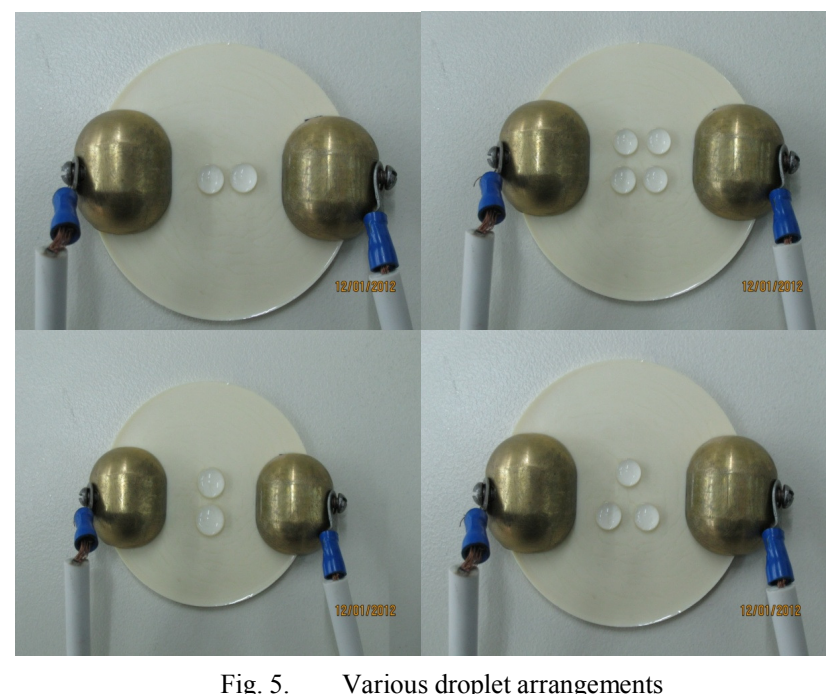

It was proposed that in the event of a surface flashover in nanocomposite polymers, the regions that are destroyed are those of epoxy resin, with the consequence of the nanoparticles coming to the surface and forming agglomerations. Such nanoparticle agglomerations contribute to reducing the degradation of the surface [16]. Moreover, SEM photographs 
of degraded polymer surfaces showed that the channels caused by surface degradation are much deeper and wider in the case of the base polymers than in the case of nanocomposites [17]. This may be due to the beneficial effect of the nanoparticles coming up to the surface and thus hindering discharge channels to be created $[17,18]$.

Regarding the flashover event in nanocomposite epoxy as well as in simple epoxy resin, one may say that under a.c. voltages more carbonization of the material was observed when simple epoxy resin was tested than when nanocomposite epoxy was tested. This is in agreement with previous research [17, $18]$.

Under ac voltages, the water droplet was first oscillating and then approaching one of the electrodes. The flashover voltage was recorded either as a flashover through the air or through the water droplets. In most experiments the water droplet(s) started oscillating at the voltage at which flashover was observed. In other experiments there was a deviation of 0.6 $\mathrm{kV}$ on average.

\section{Epoxy Resin with 1\% $\mathrm{TiO}_{2}$}

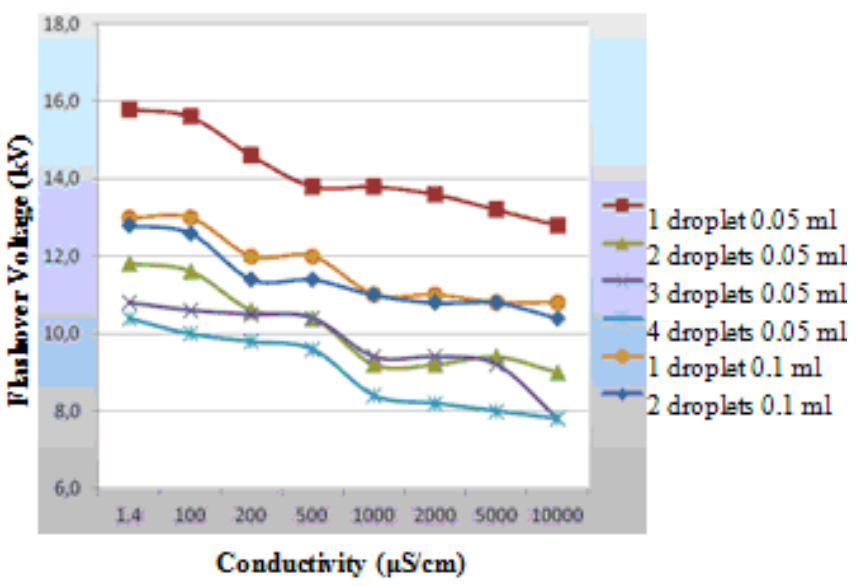

Fig. 6. Results with epoxy resin nanocomposite with $1 \%$ wt of TiO2 nanoparticles

\section{Epoxy Resin with 3\% $\mathrm{TiO}_{2}$}

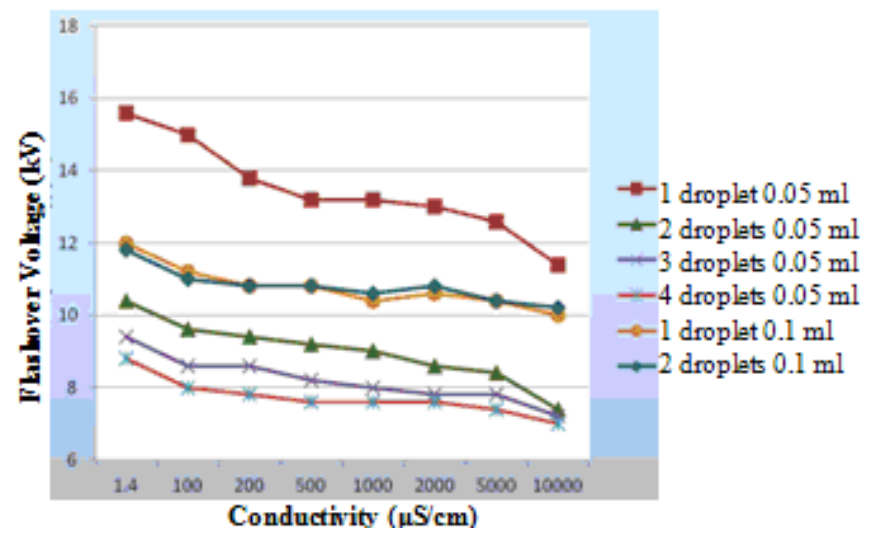

Fig. 7. Results with epoxy resin nanocomposite with $3 \%$ wt of $\mathrm{TiO} 2$ nanoparticles

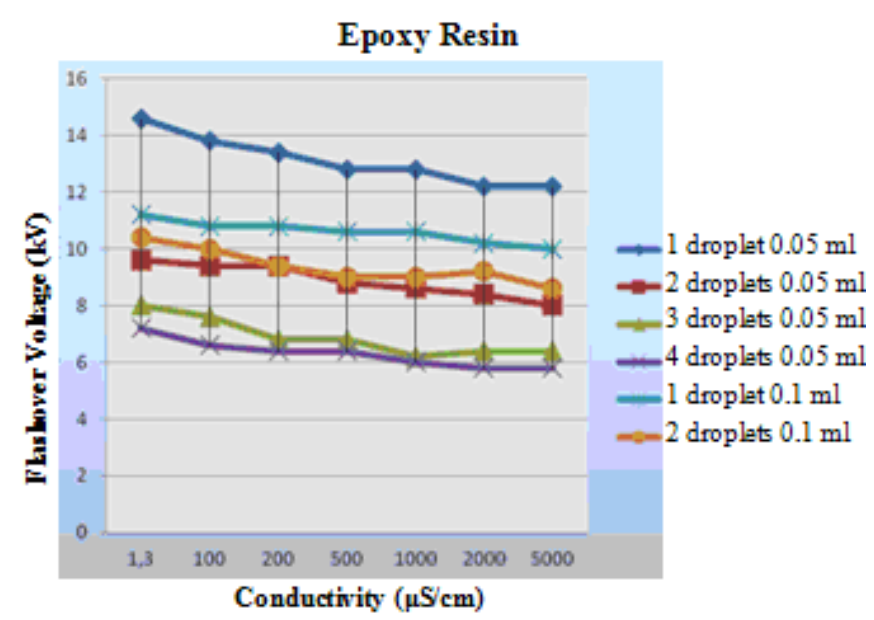

Fig. 8. Results with epoxy resin (without nanoparticles)

A criticism that may be leveled at this work is whether, given the small size of the electrodes, the applied electric field was uniform. Having in mind the small volumes of the droplets used, we consider - with the size of the electrodes employed in this work - the electric field was uniform. We plan, however, in the future more research with the same droplet volumes but with bigger electrodes.

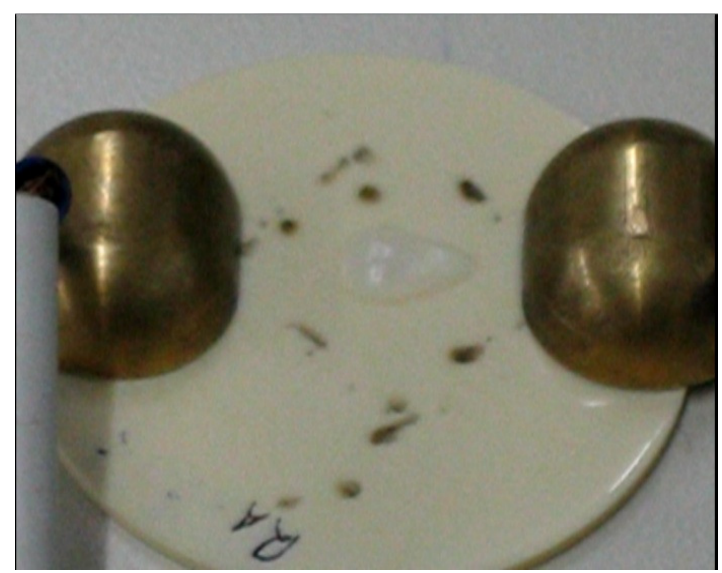

Fig. 9. Droplet deformation under the influence of electric field

\section{CONCLUSIONS}

In this paper, several factors affecting the flashover voltage on nanocomposite polymeric surfaces were investigated, such as water droplet volume, droplet number, water conductivity and positioning of droplets w.r.t. the electrodes. The flashover voltage is influenced by all these parameters. It is to be noted that in some cases, the positioning of water droplets w.r.t. the electrodes is more important than the droplet volume.

\section{REFERENCES}

[1] D. Kind, H. Kaerner, "High-voltage insulation technology", Eds. Vieweg \& Sohn, Braunschweig, Germany, 1985

[2] M. G. Danikas, A. D. Karlis, "Some observations on the dielectric breakdown and the importance of cavities in insulating materials used 
for cables and electrical machines", Advances in Electrical and Computer Engineering, Vol. 11, No. 2, pp. 123-126, 2011

[3] J. K. Nelson, "Dielectric polymer nanocomposites", Eds. Springer, Heidelberg, Germany, 2010

[4] K. Y. Lau, M. A. M. Piah, "Polymer nanocomposites in high voltage electrical insulation perspective: a review", Malaysian Polymer Journal, Vol. 6, No. 1, pp. 58-69, 2011

[5] R. Sarathi, R. K. Sahu, P. Rajeshkumar, "Understanding the thermal, mechanical and electrical properties of epoxy nanocomposites", Materials Science and Engineering: A, Vol. 445-446, pp. 567-578, 2007

[6] Y. Okazaki, M. Kozako, M. Hikita, T. Tanaka, "Effects of addition of nano-scale alumina and silica fillers on thermal conductivity and dielectric strength of epoxy/alumina microcomposites", 10th IEEE International Conference on Solid Dielectrics (ICSD), Potsdam, Germany, pp. 1-4, 2010

[7] J. K. Nelson, "The promise of dielectric nanocomposites", IEEE International Symposium on Electrical Insulation, Toronto, pp. 452-457, 2006

[8] Z. Han, J. W. Wood, H. Herman, C. Zhang, G. C. Stevens, "Thermal properties of composites filled with different fillers", ISEI 2008, IEEE International Symposium on Electrical Insulation, Vancouver, pp. 497501,2008

[9] S. Alapati, M. Joy Thomas, "Electrical treeing in polymer nanocomposites", $15^{\text {th }}$ National Power Systems Conference (NPSC), IIT Bomaby, pp. 351-355, 2008

[10] M. G. Danikas, T. Tanaka, "Nanocomposites-a review of electrical treeing and breakdown”, IEEE Electrical Insulation Magazine, Vol. 25, No. 4, pp. 19-25, 2009

[11] T. Tanaka, S. Kuge, M. Kozako, T. Imai, T. Ozaki, T. Shimizu, "Nano effects on PD endurance of epoxy nanocomposites", International Conference on Electrical Engineering, Korea, Art. No. ME1-01, pp. 1-4, 2006

[12] M. G. Danikas, "Surface pPhenomena on resin-type insulators under different electrical and non-electrical stresses in the early stage of ageing", Facta Universitatis, Vol. 13, No. 3, pp. 335-352, 2000

[13] Y. Khan, "Degradation of hydrophobic properties of composite insulators in simulated arid desert environment", International Journal of Engineering \& Technology, Vol. 10, No. 1, pp. 86-90, 2010

[14] R. Sarathi, M. G. Danikas, "Understanding discharge activity due to water droplet in epoxy nanocomposites using acoustic emission technique", Journal of Electrical Engineering, Vol. 59, No. 6, pp. 294301,2008

[15] Y. Cheng, X. Zhao, M. G. Danikas, D. D. Christantoni, P. Zairis, "A study of the behaviour of water droplets under the influence of uniform electric field in epoxy resin samples", Journal of Electrical Engineering, Vol. 63, No. 3, pp. 196-200, 2012

[16] M. Kozako, R. Kido, T. Imai, T. Ozaki, T. Shimizu, T. Tanaka, "Surface roughness change of epoxy/ $\mathrm{TiO}_{2}$ nanocomposites due to partial discharges", Proceedings of 2005 International Symposium on Electrical Insulating Materials, Kitakyushu, Japan, Vol. 3, pp. 661-664, 2005

[17] P. Maity, S. Basu, V. Parameswaran, N. Gupta, "Degradation of polymer dielectrics with nanometric metal-oxide fillers due to surface discharges", IEEE Transactions on Dielectrics and Electrical Insulation, Vol. 15, No. 1, pp. 52-62, 2008

[18] M. Kozako, S. Kuge, T. Imai, T. Ozaki, T. Shimizu, T. Tanaka, "Surface erosion due to partial discharges on several kinds of epoxy nanocomposites", Annual Report Conference on Electrical Insulation and Dielectric Phenomena (CEIDP), Nashville, USA, pp. 162-165, 2005 